\section{Depth vision in monocular frogs}

\section{DAVID INGLE*}

Neuropsychology Laboratory, McLean Hospital, Belmont, Mass. 02178

A test of depth discrimination ability of frogs was based upon the fact that animals will snap at prey-like objects within a sharply delimited zone but will orient to more distant objects. Following monocular blinding, frogs retained preoperative accuracy of discrimination between snapping and orienting distances.

The special problem of binocular vision in lower vertebrates has been long recognized on anatomic grounds, since the retino-tectal pathways of nonmammalian vertebrates are nearly always crossed (Riss \& Jakway, 1970; Ebbesson, 1970). The usual test for functional integration of these initially divided visual components has involved the abilities of fishes and birds to transfer monocular discrimination experience from eye to eye (Ingle, 1971). While these several studies leave no doubt that central integration of disparate monocular inputs exists, the question of "natural" binocular experience remains essentially unexplored. In a recent symposium, the present author provided data to indicate that complementary types of visual information could be binocularly integrated in the fog, who will detour around a barrier seen via one eye while pursuing a worm seen only by the other (Ingle, 1970). As yet, we have no good indication as to whether supplementary modes of integration also occur-i.e., instances where the use of two eyes provides better visual resolution than does use of one. The present study explores the most obvious hypothesis, that the frog's discrimination of distance would be enhanced by binocular viewing (Gaze \& Jacobson, 1962). To test this hypothesis, we have attempted to measure changes in the limits and reliability of the frog's "snapping zone" (see Ingle, 1970) before and after monocular blinding.

Twenty frogs (Rana pipiens), $21 / 2-3$ in. in length, were selected for their high level of feeding activity and for their accuracy in striking at small mealworms within the binocular field. After preliminary tests of normal snapping behavior, 12 of these were made monocular by severing the optic tract as it entered the cranium, viewed from a ventral approach. The $10 \mathrm{Ss}$ that retained a good feeding performance were retested one or

*The current study was supported by Small Grant MH 20283 from the National Institute of Mental Health, and the author was supported by a National Institute of Mental Health Research Career Development Award (K02 13175). more times for accuracy of depth estimation by the following procedure. As Fig. 1 illustrates, a yellow-tipped black wooden rod was placed at a known distance (along a marked scale) from the frog's eye within a zone extending some $15 \mathrm{deg}$ lateral to the

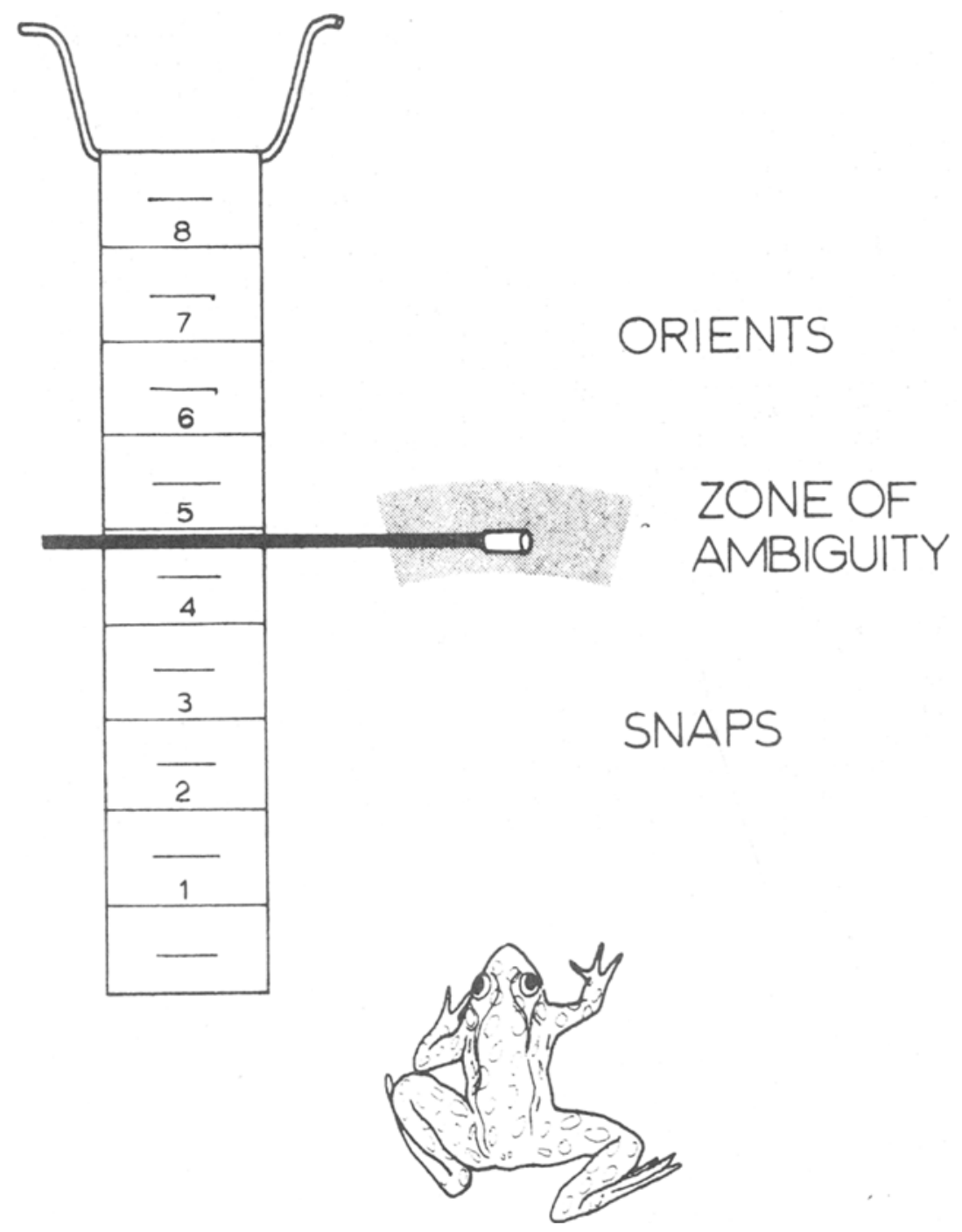

Fig. 1. Test method for determination of the accuracy of frogs' discrimination of prey distance, as judged by snapping vs orienting movements. A black rod with yellow tip moved orthogonally to the frog's body axis against a dark slate floor. Motion was restricted to a region within $15 \mathrm{deg}$ on either side of the midline. The zone of ambiguity (shaded area) is that within which a mixture of snapping and orienting responses could be recorded. For most binocular frogs, this distance proved to be about 1 in. Distance from the eye could be measured with the movable black scale on the left. 
Table 1

Best Discrimination Score Between Stimuli Set 1-in. Apart on Successive Trials*

2 to 4

$\begin{array}{ll}\text { Binocular } & \text { Days After } \\ \text { Perform- } & \text { Monocular }\end{array}$

\begin{tabular}{ccc}
$\begin{array}{c}\text { Frog. } \\
\text { Number }\end{array}$ & $\begin{array}{c}\text { ance } \\
\text { (Percent) }\end{array}$ & $\begin{array}{c}\text { Blinding } \\
\text { (Percent) }\end{array}$ \\
\hline 1 & 90 & 100 \\
2 & 80 & 100 \\
3 & 80 & 80 \\
4 & 90 & 90 \\
5 & 90 & 90 \\
6 & 90 & 90 \\
7 & 80 & 90 \\
8 & 90 & 80 \\
9 & 90 & 90 \\
10 & 90 & 90 \\
Mean Score & 87 & 90 \\
\hline
\end{tabular}

*.Maximal score is $100 \%$.

maximally discriminated the orienting zone from the snap zone. For example, a $100 \%$ discrimination score was obtained when all 10 snaps were directed at the nearer object and all 10 responses were orientations toward the same object placed $1 \mathrm{in}$. farther back. Only two locations were sampled if they gave difference between positions $1 \mathrm{in}$. apart of at least $90 \%-$-e.g., $10 / 10$ snaps vs $1 / 10$ snaps. However, if 3 or 4 adjacent positions were sampled for 10 trials each, a lower discrimination score was allowed to represent the frog's best depth resolution. For example, a typical series of tests might yield: 5 in. $-10 / 10$ snaps, $51 / 2$ in. $-9 / 10,6$ in. $-4 / 10$, and $6 \frac{1}{2}$ in. $-1 / 10$, such that the best score would be $90 \%$ minus $10 \%$ or $80 \%$.

\section{RESULTS}

The essential quantitative data are summarized in Table 1. Although some frogs showed definite inconsistency in selection of snapping responses on the first or second postoperative day, all 10 monocular frogs regained or surpassed their preoperative performance if they proved testable at all. Two Ss increased their snap zones well beyond $8 \mathrm{in}$, the limit of the measuring scale, so that an accurate measure of their "zone of ambiguity" was not possible. However, even these Ss seemed to show the original snap boundary if tested some $30 \mathrm{deg}$ to the left of the midline. Four frogs showed contracted snap zone boundaries but were still accurate in discriminating objects at a 1-in. separation. These contractions seemed to be related to the "nervousness" of these particular monocular animals during the first few postoperative days.

\section{DISCUSSION}

The results of this assessment of a binocular contribution to depth discrimination by frogs is essentially negative: monocular frogs regained fairly quickly a normal degree of distance-dependent selection between snapping and orienting responses. Some early effects of blinding were, however, quite curious: constriction of the snap zone along the midline region and snaps that fell far short of the mark. It is quite possible that severing the optic tract altered the spontaneous discharge rate of units in the now deafferented half of the visual system, thus producing a temporary disequilibrium between the two brain halves that interfered with accurate performance. Luckily, frogs recovered from these deficits, which might have encouraged incorrect conclusions about the advantages of binocularity. No evidence was obtained to support the idea that frogs share a capacity for "stereoscopic perception" with the higher mammals.

The failure to find clear evidence for a "stereoscopic" mode of vision in frogs is not too surprising. Since frogs do not show significant eye movements while in a static posture, a stereoscopic mechanism would produce double vision for all but a limited range of distances. It is possible that a limited stereoscopic zone does exist but does not coincide with the snapping zone distance as measured here. We cannot exclude the possibility that finer depth tuning is used for other types of visual discrimination-such as deciding whether or not a prey object is just behind or just ahead of a barrier. However, since monocular frogs show quite good depth judgments, it seems necessary to postulate a mechanism independent of either streeopsis of motion parallex. Perhaps, as the author has suggested elsewhere (Ingle, 1968), the frog is better able than man to obtain depth information from correlation of information about the state of lens accomodation and about the sharpness of the retinal image. Further pursuit of such questions concerning binocular integration and depth estimation in lower vertebrates seems likely to reveal some fundamental properties of nonmammalian visual systems that comparative anatomists and physiologists are just beginning to unravel.

\section{REFERENCES}

EBBESSON, S. O. E. On the organization of central visual pathways in vertebrates. Brain, Behavior \& Evolution, 1970,3, 178-194.

GAZE, R. M., \& JACOBSON, M. The projection of the binocular visual field upon the optic tecta of the frog. Quarterly Journal of Experimental Physiology, 1962, 47, 273-280.

INGLE, D. Visual releasers of prey-catching behavior in frogs and toads. Brain. Behavior \& Evolution, 1968, 1, 500-518.

INGLE, D Visuomotor functions of the frog optic tectum. Brain, Behavior \& Evolution, 1970, 3, 57-71.

INGLE, D. Vision: The experimental analysis of behavior. In W. Hoar and D. Randall (Eds.), Fish physiology. Vol. 5. New York: Academic Press, 1971.

RISS, W., \& JAKWAY, J. S. A perspective on the fundamental retinal projections of vertebrates. Brain, Behavior \& Evolution, $1970,3,30-35$. 